Article

\title{
Towards Understanding the Decomposition/Isomerism Channels of Stratospheric Bromine Species: Ab Initio and Quantum Topology Study
}

\author{
Saadullah G. Aziz ${ }^{1}$, Abdulrahman O. Alyoubi ${ }^{1}$, Shaaban A. Elroby ${ }^{1,2}$, \\ Osman I. Osman ${ }^{1}$ and Rifaat H. Hilal ${ }^{1,3, *}$
}

1 Chemistry Department, Faculty of Science, King Abdulaziz University, Jeddah B.O. 208203, Saudi Arabia; E-Mails: saziz@kau.edu.sa (S.G.A.); aalyoubi@kau.edu.sa (A.O.A.); skamel@kau.edu.sa (S.A.E.); oabdelkarim@kau.edu.sa (O.I.O.)

2 Chemistry Department, Faculty of Science, Beni Suef University, Beni Suef 6251, Egypt

3 Chemistry Department, Faculty of Science, Cairo University, Cairo 12613, Egypt

* Author to whom correspondence should be addressed; E-Mail: rhilal@kau.edu.sa; Tel.: +966-592-749-674; Fax: +026-952-292.

Academic Editor: Habil. Mihai V. Putz

Received: 11 December 2014 / Accepted: 12 March 2015 / Published: 25 March 2015

\begin{abstract}
The present study aims at a fundamental understanding of bonding characteristics of the $\mathrm{C}-\mathrm{Br}$ and $\mathrm{O}-\mathrm{Br}$ bonds. The target molecular systems are the isomeric $\mathrm{CH}_{3} \mathrm{OBr} / \mathrm{BrCH}_{2} \mathrm{OH}$ system and their decomposition products. Calculations of geometries and frequencies at different density functional theory (DFT) and Hartree-Fock/Møller-Plesset (HF/MP2) levels have been performed. Results have been assessed and evaluated against those obtained at the coupled cluster single-double (Triplet) $(\operatorname{CCSD}(\mathrm{T}))$ level of theory. The characteristics of the $\mathrm{C}-\mathrm{Br}$ and $\mathrm{O}-\mathrm{Br}$ bonds have been identified via analysis of the electrostatic potential, natural bond orbital (NBO), and quantum theory of atoms in molecules (QTAIM). Analysis of the electrostatic potential (ESP) maps enabled the quantitative characterization of the $\mathrm{Br} \sigma$-holes. Its magnitude seems very sensitive to the environment and the charge accumulated in the adjacent centers. Some quantum topological parameters, namely $\nabla^{2} \rho$, ellipticity at bond critical points and the Laplacian bond order, were computed and discussed. The potential energy function for internal rotation has been computed and Fourier transformed to characterize the conformational preferences and origin of the barriers. NBO energetic components for rotation about the $\mathrm{C}-\mathrm{Br}$ and $\mathrm{O}-\mathrm{Br}$ bonds as a function of torsion angle have been computed and displayed.
\end{abstract}


Keywords: bromine bonds; quantum topology; NBO analysis; DFT calculations; stratospheric bromine species

\section{Introduction}

The important role of bromine species in ozone depletion [1-4] in the Antarctic spring caused much research on these species in polar regions. It is assumed that the implication of stratospheric bromine species is analogues to that of the chlorinated species $[2,3,5]$. Furthermore, bromine species seem to play a potential role on ozone depletion in the marine boundary layer [6]. The reaction between bromine oxides with HOx species leading to the production of methyl bromide is of particular importance in this respect [7-9]. This process becomes more efficient in regions with high $\mathrm{OH}$ concentration. Furthermore, oxybromides which absorb light at longer wavelengths, will certainly contribute to ozone depletion.

The electronic absorption spectrum, in the gas phase, of $\mathrm{CH}_{3} \mathrm{OBr}$ has been reported in the $230<\lambda<400 \mathrm{~nm}$ range [10,11]. However, very little is known about the energetics of the photochemical/photophysical dissociation and isomerisation of $\mathrm{CH}_{3} \mathrm{OBr}$. In order to evaluate the role of bromine species, in general and that of $\mathrm{CH}_{3} \mathrm{OBr}$ in particular, in ozone depletion, knowledge of the heat of formation and the electronic characteristics of the bromine bonds are required. The isomeric system $\mathrm{CH}_{3} \mathrm{OBr} / \mathrm{CH}_{3} \mathrm{BrO} / \mathrm{BrCH}_{2} \mathrm{OH}$ is suggested to play the major role in these photochemical processes, yet no systematic study of the energies, structures and dynamics of the excited states has been published.

Quantum mechanical calculations have been carried out to study chemical bonding [12-14] and possible decomposition pathways of methyl hypobromite $\mathrm{CH}_{3} \mathrm{OBr}$ [15] in comparison with the other two similar systems, $\mathrm{CH}_{3} \mathrm{OF}$ and $\mathrm{CH}_{3} \mathrm{OCl}$ [16]. It was shown that decomposition of bromoethanol proceeds by a 1,2 $\mathrm{HBr}$ elimination process [17]. The photofragmentation processes of $\mathrm{BrCH}_{2} \mathrm{OH}$ have been studied using $a b$ initio multi-reference configuration interaction calculations for ground and excited states [12]. Several different calculations have also been carried out to examine the decomposition mechanism of the chloro and floro analogues [18-20].

The ultimate goal of the present research project is to investigate the decomposition/isomerisation dynamics of the isomeric system $\mathrm{CH}_{3} \mathrm{OBr} / \mathrm{CH}_{3} \mathrm{BrO} / \mathrm{BrCH}_{2} \mathrm{OH}$. Several different decomposition and/or isomerization channels have been proposed including the $\mathrm{HCOBr}$ (cis)/trans system. The first step to achieve this goal, which is addressed in the present communication, aims at a fundamental understanding of bonding characteristics of the $\mathrm{C}-\mathrm{Br}$ and $\mathrm{O}-\mathrm{Br}$ bonds. The target molecular systems are the isomeric $\mathrm{CH}_{3} \mathrm{OBr} / \mathrm{BrCH}_{2} \mathrm{OH}$ system and their decomposition products which are suggested to play a major role in ozone depletion processes. We are interested in evaluating the significance and relative importance of stereoelectronic effects in these systems. The characteristics of the $\mathrm{C}-\mathrm{Br}$ and $\mathrm{O}-\mathrm{Br}$ bonds will be theoretically explored and analyzed via natural bond orbital (NBO), quantum theory of atom in molecules (QTAIM) and electrostatic potential analyses. Figure 1 displays the bromine-containing species considered in the present work. 


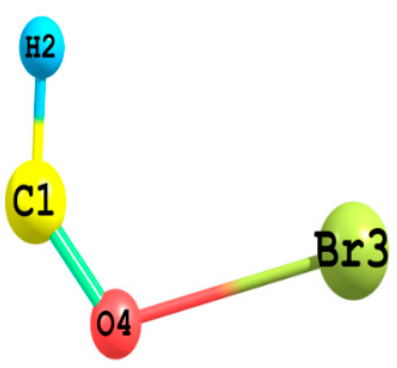

I

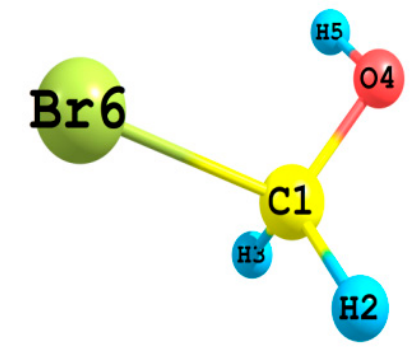

IV

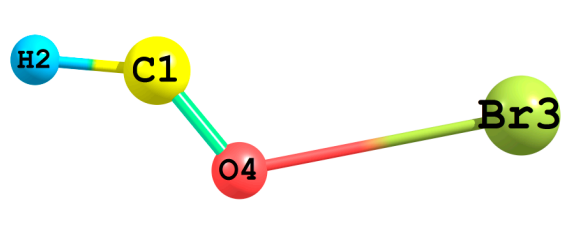

II

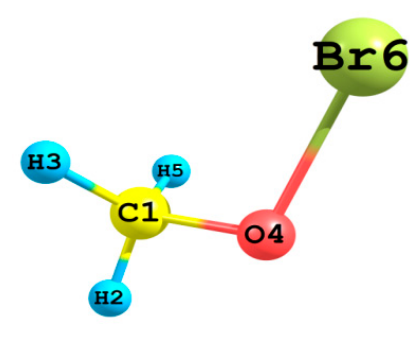

V

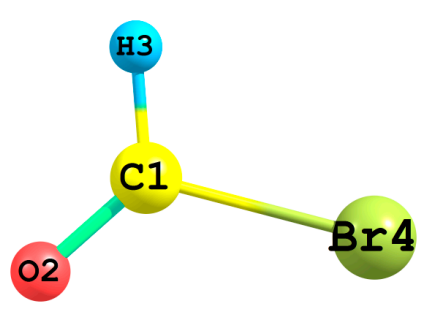

III

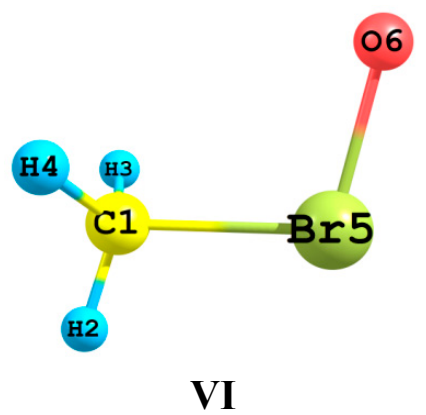

Figure 1. The optimized geometric structure and atom labeling of cis- $\mathrm{BrOCH}$ (I); trans- $\mathrm{BrOCH}$ (II); $\mathrm{BrCHO}$ (III); $\mathrm{BrCH}_{2} \mathrm{OH}$ (IV); $\mathrm{CH}_{3} \mathrm{OBr}$ (V); and $\mathrm{CH}_{3} \mathrm{BrO}$ (VI).

\section{Results and Discussion}

\subsection{Relative Stabilities of Isomeric Forms}

The appropriate theoretical model should result in as accurate and flexible wave functions as possible and should also be cost-effective, bearing in mind that these wave functions will ultimately be used in very demanding computations of the on-the-fly dynamics for the decomposition/isomerization of the bromine-containing species in their excited states. To achieve this goal, we have carried out sophisticated calculations of the geometries and frequencies at the couple-cluster single-double (triple) $\operatorname{CCSD}(\mathrm{T}) / 6-311++\mathrm{G}^{* *}$ level of theory. These very expensive calculations have been used as reference for the more economic models. Calculations at the different density functional theory (DFT) levels and at the HF-MP2 level of theory are compared to the $\operatorname{CCSD}(\mathrm{T})$ results in Table S1 of the supplementary material. Four different basis sets have also been examined in the present case. Comparison of the geometries and energies calculated using different basis sets is presented in Table S2 of the supplementary data. Careful inspection of the data in these tables reveals that acceptable level of accuracy and flexibility may be achieved at the B3LYP/aug-cc-pVTZ level of theory. In fact, this level of theory is able to produce geometries and electron density distributions of the same quality as that of the $\operatorname{CCSD}(\mathrm{T})$ level at a much reduced cost. This level will be adopted in all the calculations presented in the present communication.

Furthermore, in addition to assessing the appropriate theoretical model detailed in the aforementioned paragraph, we carried out further exhaustive calculations to determine accurate energy values to be used in thermochemical analysis of the studied systems. In such calculations, we attempt to reach complete basis set limit. Table 1 presents the total energies of the studied isomeric systems computed at the $\operatorname{CCSD}(\mathrm{T}) /$ aug-cc-pVXZ $(\mathrm{X}=2,3,4)$ level of theory. Energies extrapolated to the CBS are also given in Table 1. For the isomeric system $\mathrm{CH}_{3} \mathrm{OBr} / \mathrm{CH}_{3} \mathrm{BrO} / \mathrm{BrCH}_{2} \mathrm{OH}$, the alcohol form is more 
stable than $\mathrm{CH}_{3} \mathrm{OBr}$ and its hypervalent bromine isomer by 35.12 and $75.25 \mathrm{kcal} / \mathrm{mol}$, respectively. For the isomeric system $\mathrm{HCOBr}($ cis $) / \mathrm{HCOBr}$ (trans) $/ \mathrm{BrCHO}$, the aldehyde form is much more stable than the $\mathrm{HCOBr}($ cis $)$ and its trans form by 67.11 and $75.89 \mathrm{kcal} / \mathrm{mol}$, respectively. Increasing the quality of the basis set (mainly polarization functions) from double zeta (DZ) to quadruple-zeta (QZ) increases the relative energies by 0.28 to 0.48 atomic unit (au). Most of this energy stabilization (79\%) is due to the increase in quality in going from DZ to triple-zeta (TZ), the other $21 \%$ may be gained at a much higher cost on going to QZ. In order to evaluate the effect of the diffuse functions on the computed energies we have carried out similar CCSD(T) calculations using the cc-pVTZ basis set. Results are also included in Table 1 as numbers in parentheses. Inclusion of diffuse functions seems to lower the computed energies by about 0.02 au except for the case of the hypervalent bromine isomer $\mathrm{CH}_{3} \mathrm{BrO}$ where diffuse functions seems to be much more effective where its effect exceeds $0.09 \mathrm{au}$.

Table 1. $\operatorname{CCSD}(\mathrm{T})$ total energies (au) computed using different basis sets for the studied isomer bromine containing systems.

\begin{tabular}{ccccccc}
\hline Model & I & II & III & IV & V & VI \\
\hline aug-cc-pVDZ & -2686.10959 & -2686.09582 & -2687.40968 & -2687.40968 & -2687.35216 & -2687.27657 \\
\hline \multirow{2}{*}{ aug-cc-PVTZ } & -2686.37221 & -2686.35838 & -2687.68607 & -2687.68607 & -2687.62962 & -26875.62997 \\
& $(-2686.35370)$ & $(-2686.34045)$ & $(-2686.45778)$ & $(-2687.66428)$ & $(-2687.60696)$ & $(-2687.53326)$ \\
\hline \multirow{2}{*}{ aug-cc-pVQZ } & -2686.47047 & -2686.45571 & -26877.86817 & -2687.78682 & -2687.72951 & -2687.66377 \\
\hline CBS & -2686.50733 & -2686.49332 & -2686.61433 & -2687.82633 & -2687.77034 & -2687.70635 \\
\hline
\end{tabular}

\subsection{Structures and Vibrational Frequencies}

In the present section, we will attempt to localize and identify the structural characteristics and energetic of the $\mathrm{C}-\mathrm{Br}$ and $\mathrm{O}-\mathrm{Br}$ bonding interactions. Figure 1 presented the optimized geometries of the bromine-containing species which will be the subject of the present study.

Let us start by studying the geometric features of the isomeric system $\mathrm{CH}_{3} \mathrm{OBr} / \mathrm{CH}_{3} \mathrm{BrO} / \mathrm{BrCH}_{2} \mathrm{OH}$. The alcohol form $\mathrm{BrCH}_{2} \mathrm{OH}$ is much more stable by 33.9 and $106.2 \mathrm{kcal} / \mathrm{mol}$ than $\mathrm{CH}_{3} \mathrm{OBr}$ and its hypervalent bromine isomer $\mathrm{CH}_{3} \mathrm{BrO}$ isomer, respectively. The three isomers possess staggered structures with $C s$ symmetry.

The geometry differences are associated and focus on methyl torsions; the associated potential energy functions often exhibit significant skeletal flexing perturbations (couplings to stretching and bonding degrees of freedom) that modify an idealized rigid-rotor picture. Figure 2 compares the geometric features of the rigid-rotor limit of idealized Pople-Gordon (PG) geometry (that is localized geometry in the valence bond natural bond orbital (NBO) basis) [21] and DFT/B3LYP/aug-cc-pVTZ optimized structures in the delocalized Molecular orbital (MO) basis for the isomeric system $\mathrm{CH}_{3} \mathrm{OBr} / \mathrm{CH}_{3} \mathrm{BrO} / \mathrm{BrCH}_{2} \mathrm{OH}$. The optimized geometries deviate strikingly from idealized PG form particularly with respect to $\mathrm{Br}$...H separation and the dihedral angle specifically in case of $\mathrm{BrCH}_{2} \mathrm{OH}$. For $\mathrm{CH}_{3} \mathrm{OBr}$ the optimized $\mathrm{C}-\mathrm{O}-\mathrm{Br}$ angle open significantly $112.5^{\circ}$ thereby partially relieve the apparent steric congestion. This is a result of the mutual repulsion of the lone pair electrons localized on both the $\mathrm{Br}$ and $\mathrm{O}$ atoms. The isomeric form, $\mathrm{CH}_{3} \mathrm{BrO}$ is also enjoying a staggered conformation with the $\mathrm{C}-\mathrm{Br}-\mathrm{O}$ angle much smaller $c a .103^{\circ}$. This smaller value of the $\mathrm{C}-\mathrm{Br}-\mathrm{O}$ angle suggests that there is a $\pi$-overlap between the lone-pair electrons of the bromine atom and that of the oxygen atom. 
This $\pi$-overlap imparts partial double bond character to the $\mathrm{Br}-\mathrm{O}$ bond leading to decrease in its length to $\sim 1.7 \AA$ with the consequent decrease in electron repulsion in the carbon-bromine bond region. This point may be further clarified by NBO analysis of the total self-consistent field (SCF), deletion and delocalization energies of the tautomeric system. In these calculations, all the Rydberg and antibond orbitals, which are the non-Lewis NBO orbitals, that usually appear in the NBO analysis are deleted. The result of this deletion is the energy of the idealized NBO natural Lewis structure, with all Lewis NBOs doubly occupied. Unlike other deletions, in which there is a slight loss of variational self-consistency due to the redistributed occupancy of the deleted orbitals, the result of this deletion corresponds rigorously to the variational expectation value of the determinant of doubly occupied Lewis NBOs. This analysis is presented in Table 2. For the tautomeric system IV, V and VI, IV is the most stable by 34.742 and $77.295 \mathrm{kcal} / \mathrm{mol}$ compared to V and VI, respectively. In an ideal Lewis Structure, V is more stable than IV and VI by 23.947 and $75.054 \mathrm{kcal} / \mathrm{mol}$, respectively. The competitiveness of IV is due to the strong delocalization gaining $140.285 \mathrm{kcal} / \mathrm{mol}$. The geometric features of IV reveal the origin of its competitiveness. Thus, the $\mathrm{C}-\mathrm{Br}$ bond is now longer than $2.0 \AA$ while the $\mathrm{C}-\mathrm{O}$ bond approaches a double bond length with a value of $1.37 \AA$. The $\mathrm{O}-\mathrm{C}-\mathrm{Br}$ bond angle is $112^{\circ}$. The interaction in the $\mathrm{C}-\mathrm{O}$ bond region is markedly increased at the expense of that in the $\mathrm{C}-\mathrm{Br}$. However, the repulsive interaction involving the lone pair electrons residing on the $\mathrm{Br}$ atom causes the observed enlargement of the $\mathrm{Br}-\mathrm{C}-\mathrm{O}$ angle.

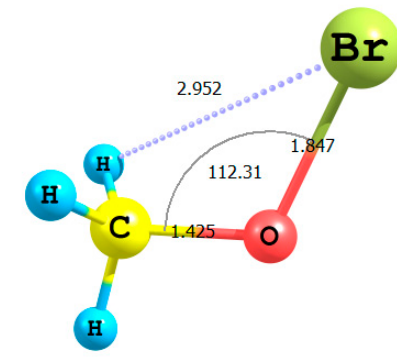

V

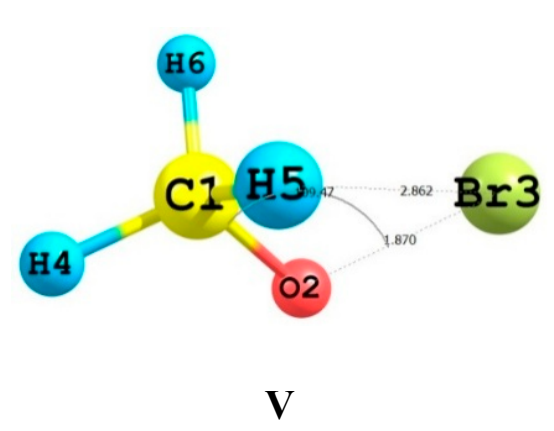

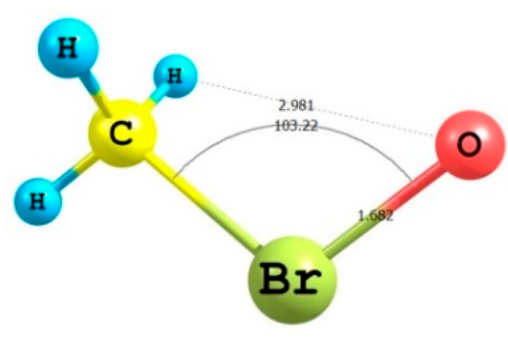

VI

Opt

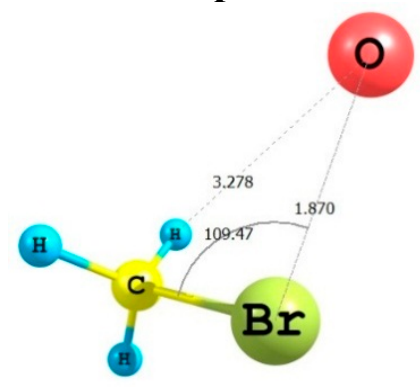

VI

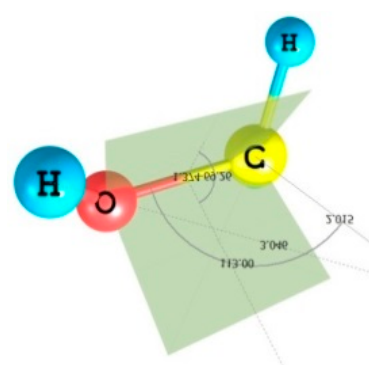

$B^{I}$

IV

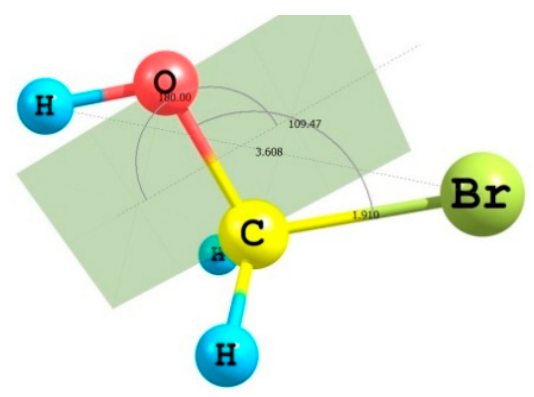

IV

PG

Figure 2. Comparison of the geometric features of the idealized PG and DFT optimized structure (Opt) for the isomeric system $\mathrm{CH}_{3} \mathrm{OBr} / \mathrm{CH}_{3} \mathrm{BrO} / \mathrm{BrCH}_{2} \mathrm{OH}$. 
Table 2. NBO analyses of the total SCF energy (au), deletion (au) and delocalization (kcal/mol) energies of the studied bromine-containing species computed at the B3LYP/aug-cc-pVTZ level of theory.

\begin{tabular}{ccccc}
\hline Substrate & Total SCF Energy & Deletion Energy & Delocalization Energy & Rotation Barrier, kcal/mol \\
\hline I & -2688.09805 & -2682.98976 & 3205.503 & \\
II & -2688.08126 & -2683.11274 & 3117.798 & \\
III & -2688.19984 & -2687.94231 & 161.600 & \\
IV & -2689.41115 & -2689.18759 & 140.285 & 2.406 \\
V & -2689.35579 & -2689.22576 & 81.596 & 0.749 \\
VI & -2689.28797 & -2689.10615 & 114.097 & 0.763 \\
\hline
\end{tabular}

The basic issue is whether the stabilizing interactions in this tautomeric system should be primarily regarded as decrease of "steric repulsion" or increase of "bonding attraction". Direct calculation of the potential energy function for rotation around the $\mathrm{C}-\mathrm{Br}$ and the $\mathrm{O}-\mathrm{Br}$ bonds and its Fourier transform analysis can be brought to bear on this issue.

The computed rotation barriers are depicted in Table 2. The large difference in magnitude between the energy barriers for $\mathrm{BrCH}_{2} \mathrm{OH}$ and that of the $\mathrm{CH}_{3} \mathrm{OBr}$ and $\mathrm{CH}_{3} \mathrm{BrO}$ indicate clearly that rotation about $\mathrm{C}-\mathrm{Br}$ and $\mathrm{O}-\mathrm{Br}$ bonds is of a completely different nature than that about the $\mathrm{C}-\mathrm{O}$ bond. Delocalization interaction underlies the large rotation barrier for rotation about the $\mathrm{C}-\mathrm{O}$ bond in $\mathrm{BrCH}_{2} \mathrm{OH}$. The origin of this rotational barrier can be identified by Fourier analysis of internal rotation function as detailed by Pople et al. [22,23]. In this analysis, the potential energy is partitioned into components, namely bond dipoles, conjugative and electrostatic repulsion contributions The Fourier transform equation can be represented as $\mathrm{V}(\varphi)=\mathrm{V}_{1}(\varphi)(1-\cos \varphi)+\mathrm{V}_{2}(\varphi)(1-\cos 2 \varphi)+$ $\mathrm{V}_{3}(\varphi)(1-\cos 3 \varphi)$, where $\varphi$ is the rotation angle, the $\mathrm{V}_{1}$ represents the interaction of bond dipoles, $\mathrm{V}_{2}$ represents the conjugative interaction, and $\mathrm{V}_{3}$ is an electrostatic bond-bond repulsion term. Fourier decomposition of the potential function for $\mathrm{CH}_{3} \mathrm{BrO}$ has been performed; results are displayed in Figure 3.

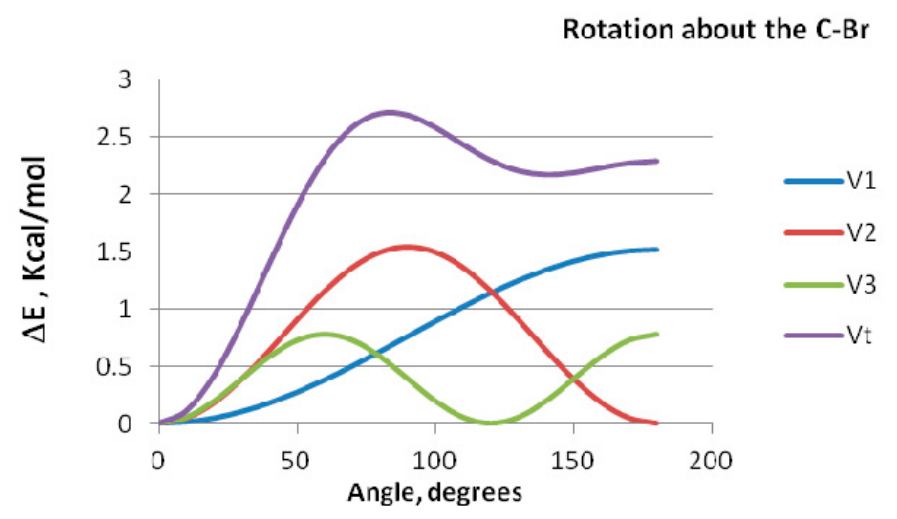

Figure 3. Fourier decomposition of the potential function for rotation about the $\mathrm{C}-\mathrm{Br}$ bond in $\mathrm{CH}_{3} \mathrm{BrO}$.

All three components of the Fourier transform contribute significantly to the potential barrier. Thus, the one-fold term shows maximum repulsion between local dipoles at $\varphi=180^{\circ}$, and maximum attraction at $\varphi=0^{\circ}$. Conjugative stabilization, as reflected by the $\mathrm{V}_{2}$ term, is maximum at $\varphi=0^{\circ}$ and $180^{\circ}$. 
The three fold electrostatic interaction component shows maximum stabilization at $\varphi=0^{\circ}$ and $120^{\circ}$ and is repulsive otherwise. The potential energy function of rotation for $\mathrm{CH}_{3} \mathrm{OBr}$ shows almost the same trend.

$\mathrm{HCOBr}$ is one of the decomposition products of the isomeric system $\mathrm{CH}_{3} \mathrm{OBr} / \mathrm{CH}_{3} \mathrm{BrO}$, which is believed to play a central role in $\mathrm{O}_{3}$ depletion in the Arctic troposphere. This species can exit in a cis(I) or a trans(II) conformations. It should be mentioned that the optimization of this species always falls into the cis-conformation, which seems to be the global minimum structure on the potential energy hypersurface. The trans-conformation can only be obtained by freezing the dihedral angle during full optimization. The cis form (I) is more stable by $10.825 \mathrm{kcal} / \mathrm{mol}$. The geometric features of this species shows the longest $\mathrm{C}-\mathrm{Br}$ bond length of an average value of $2.5 \AA$, reflecting a minimal attractive interaction of the $d$-orbitals of $\mathrm{Br}-$ with the $p$-orbitals of carbon. The $\mathrm{C}-\mathrm{O}$ bond length shows its minimum value in this species which reflects a tight binding and pronounced double bond character. This is further confirmed by a $\mathrm{C}-\mathrm{O}-\mathrm{Br}$ bond angle approaching $120^{\circ}$, a typical $s p^{2}$ hybridization scheme for the oxygen atom. The isoelectronic compound $\mathrm{BrCHO}$ (bromo formaldehyde) (III) shows the same bonding characteristics as the $\mathrm{HCOBr}$ species. Comparison of the NBO results for the total SCF, deletion and delocalization energies of the tautomeric system I, II and III is presented in Table 2. It is apparent that the structure III is more stable than I and II by 63.877 and $74.410 \mathrm{kcal} / \mathrm{mol}$, respectively. In a hypothetical Lewis structure, I is slightly more stable than III. The competitiveness of I and II are brought about by extensive hyperconjugation that gained them 3205.503 and $3117.798 \mathrm{kcal} / \mathrm{mol}$, respectively.

Table 3 displays the vibration frequencies and intensities of the relevant $\mathrm{Br}-\mathrm{O}$ and $\mathrm{C}-\mathrm{Br}$ bonds and angles. For comparison, frequencies reported in the literature $[15,20]$ are included in the same table. Data in Table 3 reveal that there are two types of $\mathrm{C}-\mathrm{O}$ bonds in the studied compounds. $\mathrm{C}=\mathrm{O}$ bonds vibrate at higher frequencies $\left(1820-1950 \mathrm{~cm}^{-1}\right.$ range) with much higher intensities than that of the $\mathrm{C}-\mathrm{O}$ stretching vibrations which appear at lower frequencies (in the $1050-1100 \mathrm{~cm}^{-1}$ range). The correspondence with the literature values are satisfactory bearing in mind that our frequency calculations are carried out within the harmonic approximation. In order to evaluate and assess the importance of anharmonic corrections of vibration modes, calculations have been performed taking in account the anharmonicity of the vibrations. The calculations were carried out in the gas phase using the VPT2 method as implemented by Barone [24,25] in the Gaussian program package [26]. In all cases, the finest DFT integration grid was selected by using SCF = tight in the command line. Results are included in Table 3. As a general trend, the anharmonic vibration frequencies are lower than the corresponding harmonic frequencies by few frequency units. There is also a clear but small effect on the computed anharmonic intensities. Furthermore, attachment of a $\mathrm{Br}$ atom to the carbon of a carbonyl group causes a blue shift and lowering of the intensity of the $\mathrm{C}-\mathrm{O}$ stretching vibration. The presence of a $\mathrm{C}=\mathrm{O}$ group shifts considerably the electron density away from the $\mathrm{O}-\mathrm{Br}$ or the $\mathrm{C}-\mathrm{Br}$ bond regions with a consequent blue shift of the $\mathrm{O}-\mathrm{Br}$ and the $\mathrm{C}-\mathrm{Br}$ stretching frequencies. Thus, in case of $\mathrm{BrOCH}$ the $\mathrm{Br}-\mathrm{O}$ stretching mode appear at a very low frequency of $160-196 \mathrm{~cm}^{-1}$ as compared to $620-730 \mathrm{~cm}^{-1}$ range for this mode in case of $\mathrm{CH}_{3} \mathrm{OBr}$, its tautomer $\mathrm{CH}_{3} \mathrm{BrO}$ and isomer $\mathrm{BrCH}_{2} \mathrm{OH}$. Calculation of the vibration spectrum of the $\mathrm{OBr}$ radical predicted the stretching vibration mode of the $\mathrm{O}-\mathrm{Br}$ bond at $742 \mathrm{~cm}^{-1}$. In case of the $\mathrm{CH}_{3} \mathrm{BrO}$ where a methyl group is attached to the bromine, $v_{\mathrm{Br}-\mathrm{O}}$ shifts but slightly down field where as such a shift became more pronounced in case of the tautomeric compound $\mathrm{CH}_{3} \mathrm{OBr}$, where $v_{\mathrm{Br}-\mathrm{O}}$ appears at $625 \mathrm{~cm}^{-1}$. 
Table 3. Vibrational Frequencies and Intensities $(\mathrm{km} / \mathrm{mol})$ for the studied bromine-containing compounds.

\begin{tabular}{|c|c|c|c|c|c|}
\hline Species & $\mathbf{v}, \mathbf{c m}^{-1}$ & $\begin{array}{l}\text { Relative } \\
\text { Intensity }\end{array}$ & $\begin{array}{c}\text { Vanharmonic, } \\
\mathbf{c m}^{-1} \\
\end{array}$ & $\begin{array}{c}\text { Relative Intensity } \\
\text { (Anharmonic) }\end{array}$ & Assignment \\
\hline \multirow{3}{*}{ cis-BrOCH (I) } & $1924.6(2068)^{\mathrm{a}}$ & 601.1 & 1905.218 & 613 & $\mathrm{C}-\mathrm{O}$ str. \\
\hline & $196.8(206)^{\mathrm{a}}$ & 65.3 & 197.912 & 59 & $\mathrm{O}-\mathrm{Br}$ str. \\
\hline & $292.2(348)^{\mathrm{a}}$ & 13.0 & 293.888 & 13 & $\mathrm{Br}-\mathrm{O}-\mathrm{C}$ angle bending \\
\hline \multirow{3}{*}{ trans-BrOCH (II) } & 1979.7 & 588.5 & 1957.464 & 590 & $\mathrm{C}-\mathrm{O}$ str. \\
\hline & 161.6 & 71.44 & 157.284 & 62 & $\mathrm{O}-\mathrm{Br}$ str. \\
\hline & 253.8 & 86.2 & 221.901 & 97 & $\mathrm{Br}-\mathrm{O}-\mathrm{C}$ angle bending \\
\hline \multirow{3}{*}{ BrCHO (III) } & $1851.0(1799)^{\mathrm{a}}$ & 466 & 1836.751 & 484 & $\mathrm{C}-\mathrm{O}$ str. \\
\hline & $633.1(663)^{\mathrm{a}}$ & 168 & 626.148 & 172 & $\mathrm{C}-\mathrm{Br}$ str. \\
\hline & $351.5(370)^{\mathrm{a}}$ & 13 & 350.071 & 14 & $\mathrm{O}-\mathrm{C}-\mathrm{Br}$ angle bending \\
\hline \multirow{3}{*}{$\mathrm{BrCH}_{2} \mathrm{OH}(\mathrm{IV})$} & $1102.7(1126)^{\mathrm{a}}$ & 286.1 & 1069.0 & 299 & $\mathrm{C}-\mathrm{O}$ str. \\
\hline & $560.5(625)^{a}$ & 107 & 549.1 & 129 & $\mathrm{C}-\mathrm{Br}$ str. \\
\hline & $284.0(306)^{\mathrm{a}}$ & 37 & 290.0 & 22 & $\mathrm{O}-\mathrm{C}-\mathrm{Br}$ angle bendin \\
\hline \multirow{3}{*}{$\mathrm{CH}_{3} \mathrm{OBr}(\mathrm{V})$} & $1054.4(1048)^{\mathrm{a}}$ & 63.2 & 1466.6 & 11 & $\mathrm{C}-\mathrm{O}$ str. \\
\hline & $998,1(581)^{\mathrm{a}}$ & 40 & 967.0 & 38 & $\mathrm{O}-\mathrm{Br}$ str. \\
\hline & $307.1(319)^{\mathrm{a}}$ & 3 & 303.5 & 4 & $\mathrm{C}-\mathrm{O}-\mathrm{Br}$ angle bending \\
\hline \multirow{3}{*}{$\mathrm{CH}_{3} \mathrm{BrO}(\mathrm{VI})$} & $657.3(723)^{b}$ & 40.1 & 648.6 & 31 & $\mathrm{Br}-\mathrm{O}$ str. \\
\hline & $516.7(530)^{b}$ & 1.9 & 505.6 & 2 & $\mathrm{C}-\mathrm{Br}$ str. \\
\hline & $207.7(222)^{b}$ & 5.5 & 208.0 & 6 & $\mathrm{C}-\mathrm{Br}-\mathrm{O}$ angle bending \\
\hline
\end{tabular}

${ }^{\mathrm{a}}$ reference $[15] ;{ }^{\mathrm{b}}$ reference [20].

\subsection{NBO-Based Quantification of Stereoelectronic Interactions}

Table 4 lists the second order perturbation estimates of the hyperconjugative energies of I, II and III. The factors that contribute to the total stabilities of tautomers include the steric hindrance, electrostatic repulsion and hyperconjugation. As shown in Figure 1, the steric hindrance and electrostatic repulsion are minimal in III compared to II and I. These two factors have led to the overall stability of III compared to I and II by 63.877 and $74.410 \mathrm{kcal} / \mathrm{mol}$, respectively. It is clear that I experiences the maximum steric effect with comparable electrostatic repulsion compared to II. Despite this, I is more stable than II by $10.533 \mathrm{kcal} / \mathrm{mol}$.

The competitiveness of I compared to II is due to the strong $\mathrm{n}_{2 \mathrm{O} 4} \rightarrow \sigma^{*} \mathrm{C} 1-\mathrm{Br} 3, \sigma^{*} \mathrm{C} 1-\mathrm{Br} 3 \rightarrow \sigma^{*} \mathrm{Cl}-\mathrm{O} 4$, $\sigma^{*} \mathrm{Cl}-\mathrm{Br} 3 \rightarrow \mathrm{n}_{2} \mathrm{O} 4$ and $\mathrm{n}_{104} \rightarrow \mathrm{n}_{20}$ interactions that yielded $187.75,11.16,13.13$ and $15.38 \mathrm{kcal} / \mathrm{mol}$ for the former and 195.27, 4.81, 6.93 and $1.23 \mathrm{kcal} / \mathrm{mol}$ for the later. It is clear that although the $\mathrm{n}_{2} \mathrm{O} 4 \rightarrow \sigma^{*} \mathrm{C} 1-\mathrm{Br} 3$ interaction favours II by $7.52 \mathrm{kcal} / \mathrm{mol}$; the later three interactions favour I by $26.70 \mathrm{kcal} / \mathrm{mol}$.

As shown in Table 4, II has been favoured by $77.172 \mathrm{kcal} / \mathrm{mol}$ due to the minimal steric hindrance, while I gained $87.704 \mathrm{kcal} / \mathrm{mol}$ compared to II as a result of the strong delocalization. That is, the overall preference of I of $10.532 \mathrm{kcal} / \mathrm{mol}$ is mainly due to hyperconjugation. Tables S3 and S4 of the supplementary data show the details of preference of III compared to I $(63.877 \mathrm{kcal} / \mathrm{mol})$ and II $(74.410 \mathrm{kcal} / \mathrm{mol})$. This means that I, II and III have fairly comparable total energies. I and II have bridged the energy gap through extensive hyperconjugation. 
Table 4. Second order perturbation $\left(\mathrm{E}^{(2)}\right)$ estimation of the hyperconjugative energies (kcal/mol) of cis-BrOCH (I), trans-BrOCH (II), and BrCHO (III) which were calculated using B3LYP/aug-cc-pVTZ level of theory.

\begin{tabular}{|c|c|c|c|}
\hline Interaction & $\mathbf{I}$ & II & III \\
\hline$\sigma_{\mathrm{Cl}-\mathrm{H} 2} \rightarrow \mathrm{n}_{2 \mathrm{O} 4}$ & 6.58 & 9.74 & - \\
\hline$\sigma_{\mathrm{C} 1-\mathrm{H} 2} \rightarrow \sigma^{*}{ }_{\mathrm{C} 1-\mathrm{Br} 3}$ & 7.71 & 8.27 & 3.52 \\
\hline$\sigma_{\mathrm{C} 1-\mathrm{Br} 3} \rightarrow \sigma_{\mathrm{C} 1-\mathrm{H} 2}^{*}$ & 3.82 & 4.18 & 1.90 \\
\hline$\sigma^{*}{ }_{\mathrm{C} 1-\mathrm{Br} 3} \rightarrow \sigma^{*}{ }_{\mathrm{C} 1-\mathrm{O} 4}$ & 11.16 & 4.81 & - \\
\hline$\sigma_{\mathrm{C} 1-\mathrm{Br} 3} \rightarrow \sigma_{\mathrm{C} 1-\mathrm{Br} 3}$ & 8.30 & 7.72 & 1.76 \\
\hline$\sigma_{\mathrm{C} 1-\mathrm{Br} 3} \rightarrow \mathrm{n}_{2 \mathrm{O} 4}$ & 13.13 & 6.93 & - \\
\hline $\mathrm{n}_{1 \mathrm{O} 4} \rightarrow \mathrm{n}_{2 \mathrm{O} 4}$ & 15.38 & 1.23 & - \\
\hline $\mathrm{n}_{1 \mathrm{O} 4} \rightarrow \sigma^{*}{ }_{\mathrm{C} 1-\mathrm{H} 2}$ & 2.01 & - & 1.32 \\
\hline $\mathrm{n}_{1 \mathrm{O} 4} \rightarrow \sigma^{*}{ }_{\mathrm{C} 1-\mathrm{Br} 3}$ & 4.02 & - & - \\
\hline $\mathrm{n}_{2 \mathrm{O} 4} \rightarrow \sigma^{*} \mathrm{C} 1-\mathrm{H} 2$ & 5.69 & 7.92 & 20.31 \\
\hline $\mathrm{n}_{2 \mathrm{O} 4} \rightarrow \sigma^{*} \mathrm{C} 1-\mathrm{Br} 3$ & 3.17 & 12.06 & 52.67 \\
\hline $\mathrm{n}_{2 \mathrm{O} 4} \rightarrow \sigma^{*}{ }_{\mathrm{C} 1-\mathrm{Br} 3}$ & 187.75 & 195.27 & - \\
\hline $\mathrm{n}_{2 \mathrm{O} 4} \rightarrow \sigma_{\mathrm{Cl}-\mathrm{O} 4}^{*}$ & 5.25 & 13.14 & - \\
\hline $\mathrm{n}_{2 \mathrm{Br} 3} \rightarrow \sigma^{*} \mathrm{Cl}-\mathrm{Br} 3$ & 2.52 & 3.03 & - \\
\hline $\mathrm{n}_{2 \mathrm{Br} 3} \rightarrow \sigma_{\mathrm{C} 1-\mathrm{O} 4}$ & - & - & 5.03 \\
\hline $\mathrm{n}_{3 \mathrm{Br} 3} \rightarrow \pi_{\mathrm{C} 1-\mathrm{O} 4}$ & - & - & 16.55 \\
\hline Total & 276.50 & 274.30 & 103.06 \\
\hline
\end{tabular}

Table 5 depicts the second order perturbation estimates of the hyperconjugative energies of IV, $\mathrm{V}$ and VI. NBO analyses of the total SCF, deletion and delocalization energies (a.u.) of IV, V and VI are listed in Tables S5-S8 of the supplementary data. It is clear that IV is more stable than V and VI by 34.741 and $77.295 \mathrm{kcal} / \mathrm{mol}$, respectively. In an ideal Lewis Structure V becomes the most stable followed by IV despite the electrostatic repulsion between the negatively charged carbon and oxygen atoms. This is perhaps due to the proximity of the two $\mathrm{Br}$ and $\mathrm{CH}_{3}$ bulky groups in both IV and VI. It is worth mentioning that $\mathrm{V}$ is more stable than $\mathrm{VI}$ by $42.553 \mathrm{kcal} / \mathrm{mol}$. Not just that, also the ideal Lewis Structure of V is more stable than that of VI by $75.054 \mathrm{kcal} / \mathrm{mol}$.

This stems from the strong steric hindrance between the two bulky $\mathrm{CH}_{3}$ and $\mathrm{Br}$ groups and the ineffective electrostatic repulsion between the negatively charged carbon and oxygen atoms and the attraction between the negatively charged carbon atom and positively charged bromine atom. However, the total energies of the two tautomers are comparable. The competitiveness of VI is due to hyperconjugation that yielded $32.501 \mathrm{kcal} / \mathrm{mol}$ compared to that of $\mathrm{V}$.

The most influential hyperconjugative interactions (cf. Table 5) ( $\left.\mathrm{n}_{2 \mathrm{O} 4}\right) \mathrm{n}_{2 \mathrm{Br} 5} \rightarrow \sigma^{*} \mathrm{C} 1-\mathrm{Br}$, $\left(\mathrm{n}_{2 \mathrm{O} 4}\right) \mathrm{n}_{2 \mathrm{Br} 5} \rightarrow \sigma^{*} \mathrm{C} 1-\mathrm{H} 3\left(\sigma^{*} \mathrm{C} 1-\mathrm{H} 5\right), \quad\left(\mathrm{n}_{2 \mathrm{Br} 6}\right) \mathrm{n}_{3 \mathrm{O} 6} \rightarrow \sigma^{*} \mathrm{Cl}-\mathrm{Br} 5\left(\sigma^{*} \mathrm{C} 1-\mathrm{O} 4\right)$ and $\mathrm{n}_{3 \mathrm{Br} 6} \rightarrow \sigma^{*} \mathrm{C} 1-\mathrm{O} 4$, have contributed $21.09,3.57,<0.5$ and $5.25 \mathrm{kcal} / \mathrm{mol}$ respectively for $\mathrm{IV} ; 5.61,5.61,1.48$ and $1.61 \mathrm{kcal} / \mathrm{mol}$ respectively for $\mathrm{V}$ and $2.30,2.19,<0.5$ and $15.83 \mathrm{kcal} / \mathrm{mol}$, respectively for VI. Therefore the origin of preference of IV is mainly due to the $\mathrm{n}_{2 \mathrm{O} 4} \rightarrow \sigma^{*} \mathrm{C} 1-\mathrm{Br} 6$ and $\mathrm{n}_{3 \mathrm{Br} 6} \rightarrow \sigma^{*} \mathrm{C} 1-\mathrm{O} 4$ donor-acceptor interactions; while the vicinal antiperiplanar $\sigma_{\mathrm{C} 1-\mathrm{H} 2} \rightarrow \sigma^{*} \mathrm{O} 4-\mathrm{Br} 6$ and lone pairs-antibonding $\mathrm{n}_{2} \mathrm{O} 4 \rightarrow \sigma^{*} \mathrm{C} 1-\mathrm{H} 3$ and $\mathrm{n}_{2 \mathrm{O} 4} \rightarrow \sigma^{*} \mathrm{Cl}-\mathrm{H} 5$ interactions contribute mostly in $\mathrm{V}$. However, the most influential hyperconjugation of VI was a lone pair donor and antibonding bond acceptor $\left(\mathrm{n}_{3 \mathrm{O}} \rightarrow \sigma^{*} \mathrm{C} 1-\mathrm{Br} 5\right)$. 
Table 5. Second order perturbation $\left(\mathrm{E}^{(2)}\right)$ estimation of the hyperconjugative energies (kcal/mol) of $\mathrm{BrCH}_{2} \mathrm{OH}(\mathrm{IV}), \mathrm{CH}_{3} \mathrm{OBr}(\mathrm{V})$, and $\mathrm{CH}_{3} \mathrm{BrO}(\mathrm{VI})$ which were calculated using B3LYP/aug-cc-pVTZ level of theory.

\begin{tabular}{|c|c|c|c|}
\hline Interaction & IV & $\mathbf{V}$ & VI \\
\hline$\sigma_{\mathrm{C} 1-\mathrm{H} 2} \rightarrow \sigma^{*}{ }_{\mathrm{O} 4-\mathrm{H} 5}\left(\sigma^{*} \mathrm{O} 4-\mathrm{Br} 6\right)\left(\sigma_{\mathrm{Br}-\mathrm{O} 6}^{*}\right)$ & 3.09 & 6.63 & 1.42 \\
\hline$\sigma_{\mathrm{O} 4-\mathrm{H} 5}\left(\sigma_{\mathrm{O} 4-\mathrm{Br} 6}\right) \rightarrow \sigma^{*} \mathrm{Cl-H} 2$ & 2.16 & 2.25 & - \\
\hline$\sigma_{\mathrm{C} 1-\mathrm{H} 2} \rightarrow \sigma^{*}{ }_{\mathrm{C} 1-\mathrm{Br} 5}$ & - & - & 1.63 \\
\hline $\mathrm{n}_{1 \mathrm{O} 4} \rightarrow \sigma^{*} \mathrm{Cl}-\mathrm{H} 2$ & 2.87 & 1.61 & - \\
\hline$\sigma_{\mathrm{C} 1-\mathrm{H} 3} \rightarrow \sigma_{\mathrm{C} 1-\mathrm{Br} 5}$ & - & - & 1.35 \\
\hline$\sigma_{\mathrm{C} 1-\mathrm{H} 4} \rightarrow \sigma^{*} \mathrm{C} 1-\mathrm{Br} 5$ & - & - & 1.36 \\
\hline$\left(\mathrm{n}_{2 \mathrm{O} 4}\right) \mathrm{n}_{2 \mathrm{Br} 5} \rightarrow \sigma^{*}{ }_{\mathrm{C} 1-\mathrm{Br} 6}\left(\sigma^{*} \mathrm{Cl}-\mathrm{H} 3\right)\left(\sigma^{*} \mathrm{Cl}-\mathrm{H} 4\right)$ & 21.09 & 5.61 & 2.30 \\
\hline$\left(\mathrm{n}_{2 \mathrm{O} 4}\right) \mathrm{n}_{2 \mathrm{Br} 5} \rightarrow \sigma_{\mathrm{C} 1-\mathrm{H} 3}^{*}\left(\sigma_{\mathrm{C} 1-\mathrm{H} 5}^{*}\right)$ & 3.57 & 5.61 & 2.19 \\
\hline $\mathrm{n}_{1 \mathrm{O} 4} \rightarrow \sigma_{\mathrm{C} 1-\mathrm{H} 3}$ & 2.95 & - & - \\
\hline$\left(\mathrm{n}_{2 \mathrm{Br} 6}\right) \mathrm{n}_{3 \mathrm{O} 6} \rightarrow \sigma^{*}{ }_{\mathrm{C} 1-\mathrm{Br} 5}\left(\sigma_{\mathrm{C} 1-\mathrm{O} 4}\right)$ & - & 1.48 & 15.83 \\
\hline $\mathrm{n}_{3 \mathrm{Br} 6} \rightarrow \sigma^{*}{ }_{\mathrm{C} 1-\mathrm{O} 4}$ & 5.25 & 1.61 & - \\
\hline$\sigma_{\mathrm{C} 1-\mathrm{Br} 5} \rightarrow \sigma_{\mathrm{Br} 5-\mathrm{O} 6}$ & - & - & 1.11 \\
\hline $\mathrm{n}_{2 \mathrm{Br} 6} \rightarrow \sigma^{*} \mathrm{Cl}-\mathrm{H} 2$ & 1.55 & - & - \\
\hline $\mathrm{n}_{2 \mathrm{Br} 6} \rightarrow \sigma^{*}{ }_{\mathrm{C} 1-\mathrm{H} 3}$ & 1.71 & - & - \\
\hline Total & 44.24 & 24.80 & 27.19 \\
\hline
\end{tabular}

The C-F bond has been shown [27] to impact the conformational preferences of organic compounds suggesting its potential utility as a molecular design tool. This impact of the conformational preferences is due to stereoelectronic effects, specifically the anomeric [28] and gaughe effects [29]. These effects may be defined as the hyperconjugative interaction of the fluorine lone pair with the $\sigma$ framework. There is no corresponding studies on the $\mathrm{C}-\mathrm{Br}$ bonds. It is thus interesting to examine, quantitatively, (1) whether such effects exists in the case of the $\mathrm{C}-\mathrm{Br}$ and $\mathrm{O}-\mathrm{Br}$ bonds; and (2) the extent to which it impacts the conformational preference of the studied compounds. To that end the interactions of the bromine lone pair $(\mathrm{nBr})$ with the $\sigma^{*} \mathrm{C}-\mathrm{H}$ MO have been computed as a function of torsion angle of rotation about the $\mathrm{C}-\mathrm{Br}$ and $\mathrm{O}-\mathrm{Br}$ bonds. Results are displayed in Figure 4a,b.

Figure 4 displays the calculated NBO energetic components for rotation about the $\mathrm{C}-\mathrm{Br}$ and $\mathrm{O}-\mathrm{Br}$ bonds as a function of torsion angle. Each of the two figures displays torsion variation of hyperconjugative interactions of the $\mathrm{Br}$ lone pairs $\mathrm{n}(2)$ and $\mathrm{n}(3)$ with the $\sigma^{*} \mathrm{C}-\mathrm{H}$ MO's. These are the leading donor-acceptor contributions arising from vicinal hyperconjugative interactions with neighboring sigma-bond. In case of $\mathrm{CH}_{3} \mathrm{OBr}$ an additional donor-acceptor interaction term results from the $\operatorname{Br}(\mathrm{n})$ interaction with the $\sigma^{*}$ acceptor orbitals of the $\mathrm{C}-\mathrm{O}$ NBO. These interaction curves bear similarity to the potential function for rotation displayed in Figure 2. It is clear from the similar vicinal environment in each of the two cases studied; the hyperconjugative details of methyl rotation are seen to be very similar. In case of $\mathrm{CH}_{3} \mathrm{BrO}$, the two $\mathrm{Br}(\mathrm{n})-\sigma^{*}(\mathrm{C}-\mathrm{H})$ interactions work in a reciprocal way but their effects are cooperative, in general. For the $\mathrm{CH}_{3} \mathrm{OBr}$ case, the $\mathrm{Br}(\mathrm{n})-\sigma^{*} \mathrm{CH}$ and the $\operatorname{Br}(n)-\sigma^{*} \mathrm{CO}$ work cooperatively in a periodic manner, whereas, the second $\operatorname{Br}(\mathrm{n})-\sigma^{*} \mathrm{CH}$ interaction behave differently. It has a destabilizing effect in the $60^{\circ}-120^{\circ}$ region. 


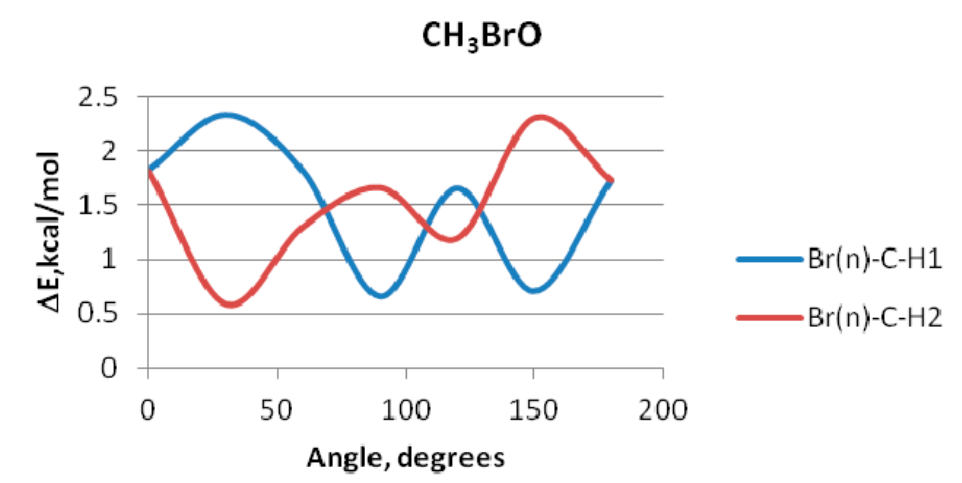

(a)

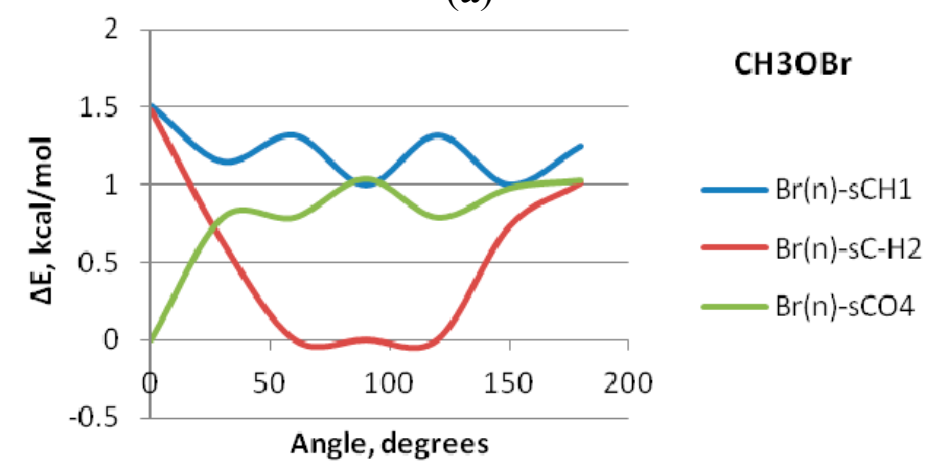

(b)

Figure 4. Variation of the leading NBO donor-acceptor interaction energies with the torsion angle of rotation about (a) $\mathrm{O}-\mathrm{Br}$ and (b) $\mathrm{C}-\mathrm{Br}$ bonds.

\subsection{Electrostatic Potentials and Quantum Chemical Topology Analyses}

The 3D electrostatic potential maps for the studied bromine species, are computed and visualized using GaussView 5.0 [30] and are displayed in Figure 5. The location of the surface maxima (red) and surface minima (blue) are computed and visualized using the Multiwfn software package [31,32]. In this software package the default isovalue is $0.001 \mathrm{au}$. The points so computed are illustrated in a $3 \mathrm{D}$ graphs in the same figure. The magnitudes of the most positive ( $\mathrm{V}_{\mathrm{S}, \max }$ ) and most negative $\left(\mathrm{V}_{\mathrm{S}, \mathrm{min}}\right)$, surface points are given in Table 6. In all molecular species studied there exists a surface maximum (positive hole) along the $\mathrm{C}-\mathrm{Br}$ and the $\mathrm{O}-\mathrm{Br}$ bonds at the end region of the bromine atom. In all cases, these surface maxima are surrounded by an electroneutral region and surface local minimum point alongside the $\mathrm{X}-\mathrm{Br}$ bond near the $\mathrm{Br}$ atom ( $c f$. Figure 5). Such a bromine positive region is referred to as the $\sigma$-hole, and seems to be a characteristic of all $\mathrm{C}$-halogen bonds [33-35].

The bromine $\sigma$-hole in $\mathrm{BrCH}_{2} \mathrm{OH}$ (IV) shows its smallest value. This is most probably due to the large positive electrostatic potential of $78.902 \mathrm{kcal} / \mathrm{mol}$ surrounding the carbon atom. The $\mathrm{Br} \sigma$-hole in $\mathrm{BrCHO}(\mathrm{III})$ is almost double that in the case of I although the bonding situations seem similar. In II, the positive potential is concentrated on $\mathrm{H}$ rather than the carbon atom. The isomeric system $\mathrm{CH}_{3} \mathrm{OBr} / \mathrm{CH}_{3} \mathrm{BrO}$ shows also different trends for both the $\sigma$-holes and the surface minima around the oxygen atoms. Thus, the hypervalent bromine shows a smaller $\sigma$-hole and almost double negative potential at the oxygen atom. These represent global minimum on the surface, its large negative value is owing to the lone pair of oxygen. In case of $\mathrm{BrOCH}($ cis $)(\mathrm{I})$ the $\sigma$-hole is huge $(107.88 \mathrm{kcal} / \mathrm{mol})$ in contrast to its trans isomer (II) which shows a much smaller value. 


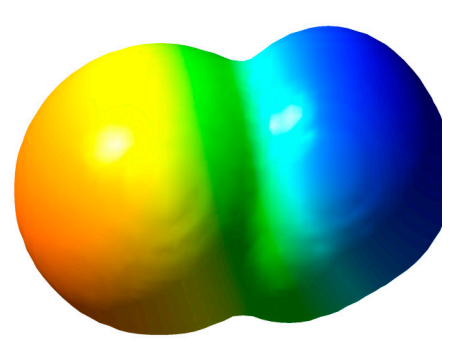

I
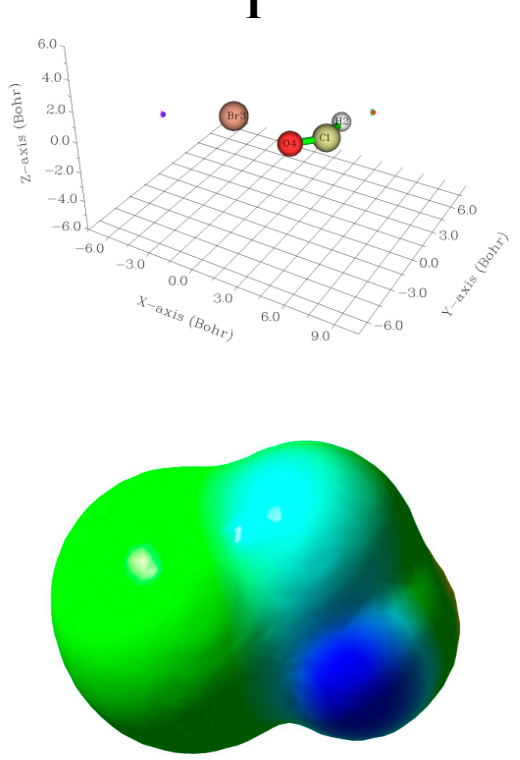

IV

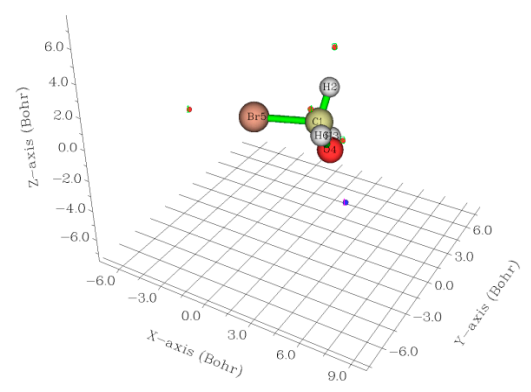

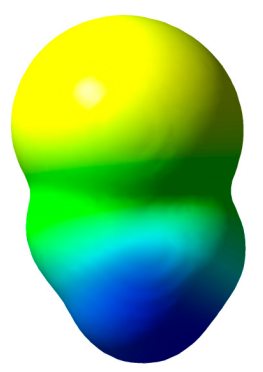

(a)

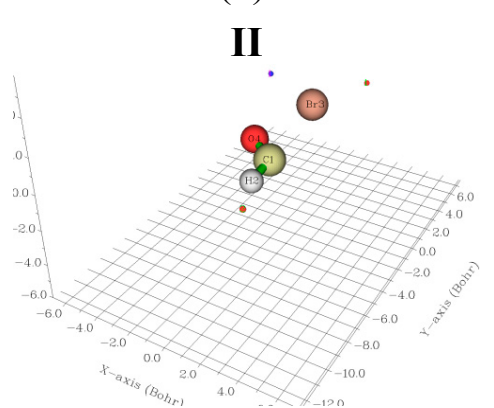

(b)

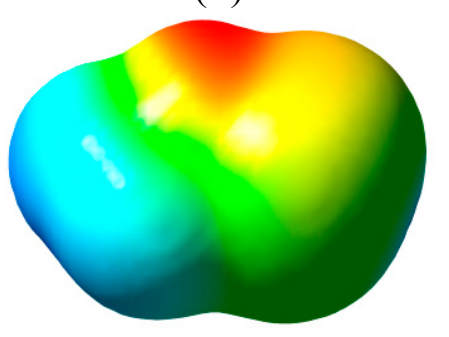

V

(a)

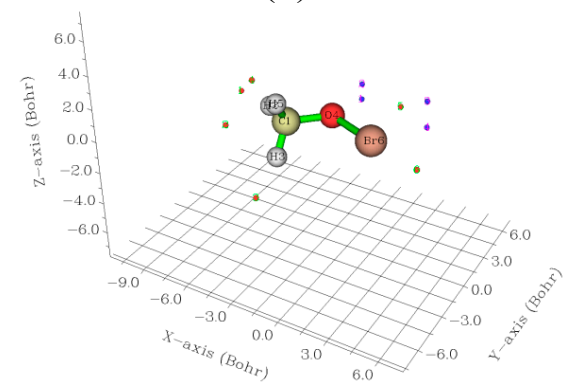

(b)

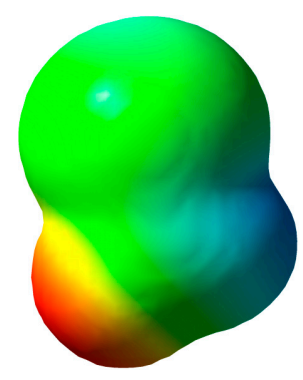

III
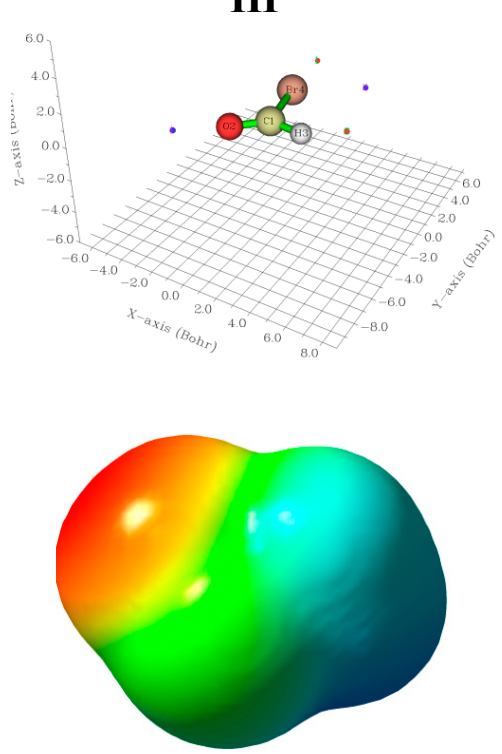

VI

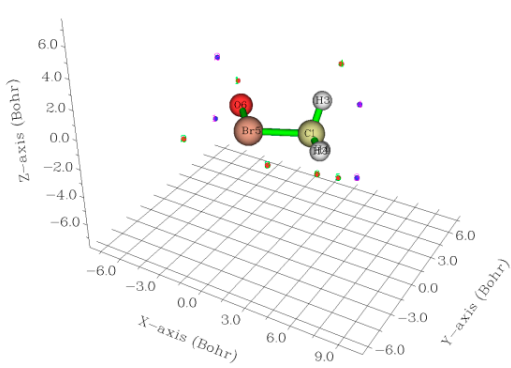

Figure 5. (a) Electrostatic potentials on the 0.001 au electron density surface; and (b) three dimensional graphs indicating the most positive maxima (red) and most negative minima (blue) surface points, for compounds I-VI.

Table 6 also shows some topological properties for the studied bromine species computed at the QTAIM level of theory. The theoretical basis of the theory has been detailed before and will not be repeated here [36]. The Laplacian of the electron density at the bond critical points (BCP) of the isomeric system $\mathrm{CH}_{3} \mathrm{OBr} / \mathrm{CH}_{3} \mathrm{BrO} / \mathrm{BrCH}_{2} \mathrm{OH}$ are all negative indicating accumulation of charge density in the $\mathrm{X}-\mathrm{Br}$ bond region. However, their magnitudes vary considerably. Thus, while $\nabla^{2} \rho(\mathrm{r})$ at the $\mathrm{O}-\mathrm{Br} \mathrm{BCP}$ is remarkably large in case of $\mathrm{CH}_{3} \mathrm{OBr}$, its value is very small in case of the alcohol form. This behavior is consistent with the values of $\mathrm{V}_{\mathrm{S} \text {, max }}$ reported in Table 5 where IV shows the 
lowest value. The three species I, II and VII show positive $\nabla^{2} \rho(\mathrm{r})$ values, indicating depletion of charge density away from the bonding region. The ellipticity values are small indicating structure stability to varying extent; its relatively largest values are associated with the hypervalent bromine compound VI.

Table 6. Computed electrostatic potential maxima $\left(\mathrm{V}_{\mathrm{S}, \max }\right)$ and minima $\left(\mathrm{V}_{\mathrm{S}, \mathrm{min}}\right)$ on the 0.001 a.u. electron-density contours (values are in $\mathrm{kcal} / \mathrm{mol}$ ), Laplacian bond order and the delocalization index $\mathrm{DI}(\mathrm{A}, \mathrm{B})$, the electron density at the BCP's and its Laplacian and ellipticity of the $\mathrm{C}-\mathrm{Br}$ and $\mathrm{O}-\mathrm{Br}$ bonds.

\begin{tabular}{cccccccc}
\hline Species & $\mathbf{V}_{\mathbf{S}, \max }$ & $\mathbf{V}_{\mathbf{S}, \min }$ & $\mathbf{L B O}$ & $\mathbf{D I}(\mathbf{A} \mid \mathbf{B})$ & $\rho(\mathbf{r})$ & $\nabla^{2} \rho(\mathbf{r})$ & $\boldsymbol{\varepsilon}$ \\
\hline $\mathrm{I}$ & $107.878(\mathrm{Br})$ & -74.725 & 0.036 & 0.335 & 0.049 & 0.148 & 0.012 \\
\hline \multirow{2}{*}{ II } & $67.630(\mathrm{H})$ & -32.094 & 0.012 & 0.037 & 0.480 & 0.094 & 0.053 \\
& $21.672(\mathrm{Br})$ & & & & & & \\
\hline III & $20.693(\mathrm{Br})$ & -56.076 & 0.298 & 1.160 & 0.122 & -0.015 & 0.066 \\
\hline IV & $10.936(\mathrm{Br})$ & -54.658 & 0.229 & 1.060 & 0.114 & -0.012 & 0.024 \\
\hline \multirow{2}{*}{ V } & $17.589(\mathrm{Br})$ & -41.306 & 0.319 & 0.928 & 0.293 & -1.162 & 0.042 \\
& & -41.305 & & & & & \\
\hline \multirow{2}{*}{ VI } & $26.623(\mathrm{Br})$ & -21.026 & 0.123 & 0.996 & 0.105 & -0.122 & 0.105 \\
& & -21.026 & & & & $-0.122 *$ & $0.105 *$ \\
\hline $\begin{array}{l}\text { VII } \\
(\mathrm{HOBr})\end{array}$ & $75.444(\mathrm{H})$ & -68.255 & 0.181 & 1.249 & 0.142 & 0.187 & 0.046 \\
\hline
\end{tabular}

* O-Br.

The final topological parameter to be discussed in the present context is the Laplacian bond order (LBO) also included in Table 5. LBO can be simply defined as $\nabla^{2} \rho(\mathrm{r})$ in fuzzy overlap space and may be given [37] by $\mathrm{LBO}_{\mathrm{A}, \mathrm{B}}=-10 \times \int \mathrm{W}_{\mathrm{A}}(\mathrm{r}) \mathrm{W}_{\mathrm{B}}(\mathrm{r}) \nabla^{2} \rho(\mathrm{r}) \mathrm{dr}$, where the integration goes for negative values of $\nabla^{2} \rho(r)$ only $\left(\nabla^{2} \rho(r)<0\right)$ where $w$ is a weighting function proposed by Becke representing the fuzzy space. A detailed discussion of LBO is given elsewhere [36]. In case of fuzzy partitioning of the atomic space there are no clear boundaries between adjacent atoms. This is in contrast to the basis on which the QTAIM is based where it adopts a discrete partitioning of the atomic space between adjacent atoms. Therefore, no overlap spaces between atoms and consequently their atomic spaces are mutually exclusive. LBO values given in Table 5 seems to describe bonding in the $\mathrm{C}-\mathrm{Br}$ and $\mathrm{O}-\mathrm{Br}$ regions better than $\nabla^{2} \rho(\mathrm{r})$. Linearly fitting the computed $\mathrm{LBO}$ values to $v \mathrm{C}-\mathrm{Br}$ and $v \mathrm{O}-\mathrm{Br}$ results in good correlations, with the former performing even better, with a correlation coefficient of 0.99 . The computed LBO values reflects nicely the relative strength of the $\mathrm{X}-\mathrm{Br}$ bonds studied in the present work. There exists a linear correlation of $\nabla^{2} \rho$ всг with the vibrational frequencies, although of much lower quality. Thus, for $\mathrm{C}-\mathrm{Br}$, the correlation coefficient is 0.74 and the fit invert sign of $\nabla^{2} \rho \mathrm{BCP}$ is at its high end and thus exhibits a wrong nature of the $\mathrm{C}-\mathrm{Br}$ bond. In the case of $\mathrm{O}-\mathrm{Br}$, the fit is of a higher quality $\left(r^{2}=0.81\right)$ and is the correct sign of the $\nabla^{2} \rho_{\mathrm{BCP}}$. The delocalization index DI(A,B) measures the average number of electrons delocalized (shared) between atoms A and B. If $A$ and $B$ are directly connected by a bond path then DI(A,B) is termed bond index. Values of DI(A,B) given in Table 6 elaborate upon the above mentioned picture and show a wide variations ranging from 0.03 to 1.3. The $\mathrm{O}-\mathrm{Br}$ bond seems illustrative in this respect. Thus, for the isomeric HOCBr system, the 
$\mathrm{DI}(\mathrm{A}, \mathrm{B})$ index is 10 times as great for the cis-over the trans form. On the other hand, $\mathrm{DI}(\mathrm{A}, \mathrm{B})$ index for the $\mathrm{BrCH}_{2} \mathrm{OH} / \mathrm{CH}_{3} \mathrm{OBr} / \mathrm{CH}_{3} \mathrm{BrO}$ system, show much fewer variations, and show almost constant accumulation of charge in the $\mathrm{C}-\mathrm{Br}$ and $\mathrm{O}-\mathrm{Br}$ bond regions. Ellipticity values given in Table 6 elaborate on the covalent nature of both $\mathrm{C}-\mathrm{Br}$ and $\mathrm{O}-\mathrm{Br}$ but do not show a clear trend for their relative strength and give in general poor correlations with the vibrational frequency values.

\section{Computational Details}

All quantum chemical calculations carried out in the present work were performed using the Gaussian 09 suite of programs [26]. Full geometry optimizations for each and every species studied have been carried out using different DFT functionals namely, the B3LYP [38,39], M06-2x [40] and PBE1PBE [41] methods and Møller-Plesset perturbation theory [42] at the MP2 level. Energies of the isomeric systems studied were determined at high level of theory using the coupled cluster theory including the iterative triplets, $\operatorname{CCSD}(\mathrm{T})$ [43]. Furthermore, different basis sets have also been employed in the present work, namely the triple zeta Gaussian basis set 6-311++G** [44] and the set of augmented correlated basis set aug-cc-pVXZ $(X=2,3,4)$ [45]. Extrapolation to the basis set limit has been carried out using the extrapolation equation of Halkier et al. [46].

Chemical bonds were studied and characterized at the QTAIM level of theory [47-49]. Topological analysis and the evaluation of local properties were performed with AIMII software [50] using the wave functions calculated at aug-cc-pVXZ level. NBO analysis [51-53] was performed at the B3LYP/aug-cc-pVTZ level using the NBO5.0 program implemented in the Gaussian09 interface. Surface electrostatic potential maxima and minima points were computed and visualized using the Multiwfn software package [31,32].

\section{Conclusions}

The present work presents detailed analyses of the geometric features of two isomeric bromine systems, namely $\mathrm{CH}_{3} \mathrm{OBr} / \mathrm{CH}_{3} \mathrm{BrO} / \mathrm{BrCH}_{2} \mathrm{OH}$ and the system of decomposition products $\mathrm{BrOCH}($ cis $) / \mathrm{BrOCH}($ trans $) / \mathrm{BrCHO}$. The basic issue here is what type of stereoelectronic effects govern the geometric features in these tautomeric systems. The three isomers possess staggered structures with Cs symmetry. The geometry differences are associated and focus on methyl torsions; the associated potential energy functions often exhibit significant skeletal flexing perturbations (couplings to stretching and bonding degrees of freedom) that modify an idealized rigid-rotor picture. The optimized geometries deviate strikingly from an idealized PG form, particularly with respect to $\mathrm{Br}$...H separation and the dihedral angle. Direct calculation of the potential energy function for rotation around the $\mathrm{C}-\mathrm{Br}$ and the $\mathrm{O}-\mathrm{Br}$ bonds and its Fourier transform analysis brought to bear on this issue. The characteristics of the $\mathrm{C}-\mathrm{Br}$ and $\mathrm{O}-\mathrm{Br}$ bonds and their cooperative effect have been explored within the QTAIM framework and analysis of the electrostatic potential maps. Various topological parameters have been computed analyzed and discussed. Analysis of the ESP maps indicate that the magnitude of the $\sigma$-hole around the $\mathrm{Br}$ atom along the $\mathrm{X}$ - $\mathrm{Br}$ bond is very sensitive to the environment and the charge accumulated in the adjacent centers. The computed LBOs show better ability to discriminate bonding strength than the $\nabla^{2} \rho \mathrm{BCP}$ and Ellipticity, and have good direct correlation with 
bond vibrational frequency. This is probably due to the fact that LBO is computed in fuzzy atomic space and hence is a measure of the electron density in the whole bonding region.

\section{Supplementary Materials}

Supplementary materials can be found at http://www.mdpi.com/1422-0067/16/04/6783/s1.

\section{Acknowledgments}

This Project was funded by the King Abdulaziz City for Science and Technology (KACST) under grant number 11-ENV 1995-03. The authors, therefore, acknowledge with thanks KACST for support for scientific research. Also, the authors appreciate the kind cooperation provided by the Deanship of Scientific Research (DSR), King Abdulaziz University.

\section{Author Contributions}

Rifaat H. Hilal suggested the research point and did some of the writing up. Abdulrahman O. Alyoubi, Osman I. Osman, Shaaban A. Elroby and Saadullah G. Aziz carried out the calculations and worked out the figures. Rifaat H. Hilal and Shaaban A. Elroby contributed mostly in the discussion and the writing up of the manuscript. All authors shared equally the revision of the manuscript.

\section{Conflicts of Interest}

The authors declare no conflict of interest.

\section{References}

1. WMO/UNEP. Scientific Assessment of Ozone Depletion. Report No.37; WMO: Geneva, Switzerland, 1994.

2. Barrie, L.A.; Bottenheim, J.W.; Schnell, R.C.; Crutzen, P.J.; Rasmussen, R.A. Ozone destruction and photochemical reactions at polar sunrise in the lower Arctic atmosphere. Nature 1988, 334, 138-141.

3. Platt, U. Arctic Troposphere Ozone Chemistry (ARCTOC). Final Report to European Union; EU: Brussels, Belgium, 1996.

4. Farman, J.C.; Gardiner, B.G.; Shanklin, J.D. Large losses of total ozone in Antarctica reveal seasonal $\mathrm{ClO}_{\mathrm{x}} / \mathrm{NO}_{\mathrm{x}}$ interaction. Nature 1985, 315, 207-210.

5. Wofsy, S.C.; McElroy, M.B.; Yung, Y.L. The chemistry of atmospheric bromine. Geophys. Res. Lett. 1975, 2, 215-218.

6. Vogt, R.; Crutzen, P.J.; Sander, R. A mechanism for halogen release from sea-salt aerosol in the remote marine boundary layer. Nature 1996, 383, 327-330.

7. Poulet, G.; Pirre, M.; Maguin, F.; Ramaroson, R.; le Bras, G. Role of the $\mathrm{BRO}+\mathrm{HO}_{2}$ reaction in the stratospheric chemistry of bromine. Geophys. Res. Lett. 1992, 19, 2305-2308.

8. Larichev, M.; Maguin, F.; le Bras, G.; Poulet, G. Kinetics and Mechanism of the $\mathrm{BrO}+\mathrm{HO}_{2}$ Reaction. J. Phys. Chem. 1995, 99, 15911-15918. 
9. Elrod, M.J.; Meads, R.F.; Lipson, J.B.; Seeley, J.V.; Molina, M.J. Temperature dependence of the rate constant for the $\mathrm{HO}_{2}+\mathrm{BrO}$ reaction. J. Phys. Chem. 1996, 100, 5808-5812.

10. Benter, T.; Feldman, C.; Kirchner, U.; Schmidt, M.; Schindler, R.N. UV/VIS-absorption spectra of $\mathrm{HOBr}$ and $\mathrm{CH}_{3} \mathrm{OBr} ; \mathrm{Br}\left({ }^{2} \mathrm{P}_{3 / 2}\right)$ atom yields in the photolysis of $\mathrm{HOBr}$. Ber. Bunsen-Ges. Phys. Chem. 1995, 99, 1144-1147.

11. Orlando, J.J.; Burkholder, J.B. Gas-phase UV/Visible absorption spectra of $\mathrm{HOBr}$ and $\mathrm{Br}_{2} \mathrm{O}$. J. Phys. Chem. 1995, 99, 1143-1150.

12. Putz, M.V. Path integrals for electronic densities, reactivity indices, and localization functions in quantum systems. Int. J. Mol. Sci. 2009, 10, 4816-4940.

13. Putz, M.V. Density functionals of chemical bonding. Int. J. Mol. Sci. 2008, 9, 1050-1095.

14. Putz, M.V. Markovian approach of the electron localization functions. Int. J. Quantum Chem. 2005, 105, 1-11.

15. Demetrios, K.; Papayannis, Drougas, E.; Kosmas, A.M. Ab initio and RRKM calculations for the decomposition channels of $\mathrm{CH}_{3} \mathrm{OBr}$ and $\mathrm{BrCH}_{2} \mathrm{OH}$. Chem. Phys. 2002, 282, 305-314.

16. Theys, N.; van Roozendael, M.; Hendrick, F.; Yang, X.; de Smedt, I.; Richter, A.; Begoin, M.; Errera, Q.; Johnston, P.V.; Kreher, K.; et al. Global observations of tropospheric BrO columns using GOME-2 satellite data. Atmos. Chem. Phys. 2011, 11, 1791-1811.

17. Yvon-Lewis, S.A.; Saltzman, E.S.; Montzka, S.A. Recent trends in atmospheric methyl bromide: Analysis of post-Montreal Protocol variability. Atmos. Chem. Phys. 2009, 9, 5963-5974.

18. Lesar, A.; Schnell, M.; Muhlhauser, M.; Peyerimhoff, S.D. Ab initio investigation of the photofragmentation of Bromomethanol. Chem. Phys. Lett. 2002, 366, 350-356.

19. Guha, S.; Francisco, J.S. Structures, vibrational spectra, and relative energetics of $\mathrm{CH}_{3} \mathrm{BrO}_{3}$ isomers. J. Phys. Chem. A 2000, 104, 3239-3245.

20. Guha, S.; Francisco, J.S. Density-functional study of the equilibrium structures, vibrational spectra, and energetics of $\mathrm{CH}_{3} \mathrm{OBr}$ and $\mathrm{CH}_{3} \mathrm{BrO}$. J. Phys. Chem. 1998, A102, 9970-9974.

21. Pople, J.A.; Gordon, M. Molecular orbital theory of the electronic structure of organic compounds. I. Substituent effects and dipole moments. J. Am. Chem. Soc. 1967, 89, 4253-4261.

22. Schaefer, T.; Wildman, T.A.; Salman, R.H. The perpendicular conformation of 2-hydroxythiophenol. Intramolecular hydrogen bonding to a specific lone pair. J. Am. Chem. Soc. 1980, 102, 107-110.

23. Schaefer, T.; Salman, S.R.; Wildman, T.A.; Clark, P.D. Conformational consequences of intramolecular hydrogen bonding by $\mathrm{OH}$ to the directional lone-pair of sulfur in derivatives of methyl phenyl sulfide, diphenyl sulfide, and diphenyl disulfide. Can. J. Chem. 1982, 60, 342-348.

24. Barone, V. Vibrational zero-point energies and thermodynamic functions beyond the harmonic approximation. J. Chem. Phys. 2004, 120, 3059-3065.

25. Barone, V. Anharmonic vibrational properties by a fully automated second-order perturbative approach. J. Chem. Phys. 2005, 122, doi:10.1063/1.1824881.

26. Frisch, M.J; Trucks, G.W.; Schlegel, H.B.; Scuseria, G.E.; Robb, M.A.; Cheeseman, J.R.; Scalmani, G.; Barone, V.; Mennucci, B.; Petersson, G.A.; Nakatsuji, H.; Caricato, M.; et al. Gaussian 09 Suite of Programs; Gaussian, Inc.: Wallingford, CT, USA, 2009.

27. Hunter, L. The C-F bond as a conformational tool in organic and biological chemistry. Beilstein J. Org. Chem. 2010, 38, 1-14. 
28. Trapp, M.L.; Watts, J.K.; Weinberg, N.; Pinto, B.M. Component analysis of the $\mathrm{X}-\mathrm{C}-\mathrm{Y}$ anomeric effect $(\mathrm{X}=\mathrm{O}, \mathrm{S} ; \mathrm{Y}=\mathrm{F}, \mathrm{OMe}, \mathrm{NHMe})$ by DFT molecular orbital calculations and natural bond orbital analysis. Can. J. Chem. 2006, 84, 692-701.

29. O'Hagan, D. Organofluorine chemistry: Synthesis and conformation of vicinal fluoromethylene motifs. J. Org. Chem. 2012, 77, 3689-3699.

30. GaussView, Version 5; Dennington, R., Keith, T., Millam, J., Eds.; Semichem Inc.: Shawnee Mission, KS, USA, 2009.

31. Lu, T.; Chen, F. Multiwfn: A multifunctional wavefunction analyzer. J. Comp. Chem. 2012, 33, 580-592.

32. Lu, T.; Chen, F. Quantitative analysis of molecular surface based on improved Marching Tetrahedra algorithm. J. Mol. Graph. Model. 2012, 38, 314-323.

33. Politzer, P.; Murray, J.S. Halogen bonding: An interim discussion. Chemphyschem 2013, 14, 278-294.

34. Clark, T.; Hennemann, M.; Murray, J.S. Halogen bonding: The $\sigma$-hole. J. Mol. Model. 2007, 13, 291-296.

35. Politzer, P.; Murray, J.S.; Clark, T. Halogen bonding: An electrostatically-driven highly directional noncovalent interaction. Phys. Chem. Chem. Phys. 2010, 12, 7748-7757.

36. Popelier, P.L.A. Atoms in Molecules. An Introduction; Pearson Education: Harlow, UK, 2000.

37. Lu, T.; Chen, F. Bond order analysis based on the Laplacian of electron density in fuzzy overlap space. Phys. Chem. A 2013, 117, 3100-3108.

38. Becke, A.D. Density-functional thermochemistry. IV. A new dynamical correlation functional and implications for exact-exchange mixing. J. Chem. Phys. 1996, 104, 1040-1046.

39. Becke, A.D. Density-functional thermochemistry. V. Systematic optimization of exchange-correlation functionals. J. Chem. Phys. 1997, 107, 8554-8560.

40. Zhao, Y.; Truhlar, D.G. The M06 suite of density functionals for main group thermochemistry, thermochemical kinetics, noncovalent interactions, excited states, and transition elements: Two new functionals and systematic testing of four M06-class functionals and 12 other functionals. Theor. Chem. Acc. 2008, 120, 215-241.

41. Ernzerhof, M.; Perdew, J.P. Generalized gradient approximation to the angle- and system-averaged exchange hole. J. Chem. Phys. 1998, 109, 3313-3320.

42. Becke, A.D. Density functional thermochemistry. III. The role of exact exchange. J. Chem. Phys. 1993, 98, 5648-5652.

43. Gordon, M.S. The isomers of silacyclopropane. Chem. Phys. Lett. 1980, 76, 163-168.

44. Raghavachari, K.; Trucks, G.W.; Pople, J.A.; Head-Gordon M. A fifth-order perturbation comparison of electron correlation theories. Chem. Phys. Lett. 1989, 157, 479-483.

45. Dunning, T.H., Jr. Gaussian basis sets for use in correlated molecular calculations. I. The atoms boron through neon and hydrogen. J. Chem. Phys. 1989, 90, 1007-1023.

46. Halkier, A.; Helgaker, T.; Jørgensen, P.; Klopper, W.; Koch, H.; Olsen, J.; Wilson, A.K. Basis-set convergence in correlated calculations on $\mathrm{Ne}, \mathrm{N}_{2}$, and $\mathrm{H}_{2} \mathrm{O}$. Chem. Phys. Lett. 1998, 286, $243-252$.

47. Bader, R.F.W. Atoms in Molecules. A Quantum Theory; Oxford Science Publications, Clarendon Press: London, UK, 1990.

48. Cort'es-Guzman, F.; Bader, R.F.W. Complementarity of QTAIM and MO theory in the study of bonding in donor-acceptor complexes. Coord. Chem. Rev. 2005, 249, 633-662. 
49. Matta, C.F.; Boyd, R.J. The Quantum Theory of Atoms in Molecules: From Solid State to DNA and Drug Design; Wiley-VCH: Weinheim, Germany, 2007.

50. Keith, T.A. AIMAll (Version 11.04.03). 2011. Available online: http://aim.tkgristmill.com (accessed on 3 October 2011).

51. Glendening, E.D.; Weinhold, F.J. Natural resonance theory: I. General formalism. Comput. Chem. 1998, 19, 593-609.

52. Glendening, E.D.; Weinhold, F.J. Natural resonance theory: II. Natural bond order and valency. Comput. Chem. 1998, 19, 610-627.

53. Glendening, E.D.; Badenhoop, J.K.; Weinhold, F.J. Natural resonance theory: III. Chemical applications. Comput. Chem. 1998, 19, 628-646.

(C) 2015 by the authors; licensee MDPI, Basel, Switzerland. This article is an open access article distributed under the terms and conditions of the Creative Commons Attribution license (http://creativecommons.org/licenses/by/4.0/). 